\title{
ЯЗЫКОЗНАНИЕ
}

УДК 81-119

O. В. Сарьгёз

ЯЗЫКОВЫЕ АВТО- И ГЕТЕРОСТЕРЕОТИПЫ В ТУРЕЦКОМ ЯЗЫКЕ

Санкт-Петербургский государственный университет, Российская Федерация, 199034, Санкт-Петербург, Университетская наб., 7-9

В статье дано определение категории «языковой стереотип», рассматриваются его виды авто- и гетеростереотипы - на примере устойчивых выражений, клише и фразеологических единиц турецкого языка. Полиэтничность Турции анализируется через призму языковых стереотипов. Явление социальной адаптации и невладение кодом «свой - чужой» объясняются в свете социолингвистических подходов. Библиогр. 28 назв.

Ключевые слова: лингвокультурология, языковой стереотип, турецкий язык, турецкий фразеологизм, турецкое клише, турецкая фразеология, тюркское языкознание, тюркские языки.

\section{LANGUAGE AUTOSTEREOTYPES AND HETEROSTEREOTYPES İN TURKISH}

\section{O. V.Sarygoz}

Saint Petersburg State University, 7-9, Universitetskaya nab., St. Petersburg, 199034, Russian Federation

The article defines the 'linguistic ethnic stereotype' category in relation to the Turkish language, discusses its 2 types, namely, language auto and heterostereotypes based on the example of fixed expressions, clichés and idiomatic units. Ethnic stereotypes may provide a useful social psychological perspective in which to consider intergroup relations between national groups. The present study aims to contribute to the ethnic psycholinguistic research of Turkish language as well as to fill in the gap that exists in this under-researched field. The purpose of this study is to investigate the links between language auto and heterostereotypes of modern Turkish language and the state of ethnic relations within Turkish society: their perceptions of members of various nationalities inhabiting multi-ethnic and multi-religious Turkey. A more narrow aim is to provide a pilot description and explanation to the given formulaic sentences.

Limited research on language issues is also reviewed, 61 formulas have been analyzed and our findings indicate that auto-stereotypes are generally more positive than hetero-stereotypes. This paper focuses on Turkish foreign language teachers' perceptions of culture teaching. The context in which cross-cultural contacts took place seemed to be an important variable.

The results and the methodology may be useful to multinational corporations in identifying sources of potential conflict and misunderstanding between different cultural groups working together. Refs 28.

Keywords: linguistic stereotype, the Turkish language, the Turkish idiom, the Turkish cliches, Turkish phraseology, Turkic linguistics, Turkic languages.

() Санкт-Петербургский государственный университет, 2017 
Мы видим, слышим и вообще воспринимаем мир именно так, а не иначе главным образом благодаря тому, что наш выбор при его интерпретации предопределяется языковыми привычками нашего общества.

Э. Сепир

Настоящая работа представляет собой этнопсихолингвистический анализ устойчивых выражений современного турецкого языка, содержащих стереотипы. Впервые в тюркологии будет предпринята попытка проанализировать ментальность народа через призму языка. Клише, пословицы, поговорки и фразеологизмы, являя собой элементы языковой картины мира турецкого народа, отражают и фиксируют культуру в языке и дискурсе. Через них можно установить непосредственную связь с национальной картиной мира того или иного народа, подвергнуть анализу его языковое сознание, воссоздать картину культурных ценностей, а в нашем случае - проанализировать и установить особенности восприятия им других народов и самих себя.

Термин «стереотип», придя в нашу речь из типографского дела, где он обозначал форму для печати оттисков (греч. stereos 'твердый’ и typos ‘отпечаток'), получил «вторую жизнь» в начале прошлого века, когда на него обратили внимание ученые различных специальностей (социологи, психологи, лингвисты и др.).

Наиболее общее определение термина дал американский лингвист Д. Мацумото, который охарактеризовал стереотип как обобщенное представление «о группах людей, их основополагающих психологических характеристиках или чертах личности» $[1$, с. 42$]$.

Российской лингвистической школой предложена практически аналогичная дефиниция. Под стереотипом ее представители понимают «стандартное мнение о социальных группах или отдельных лицах как представителях этих групп» [2, c. 117].

Западные (У.Липпман, Х. Патнэм, Е. Бартминский) и отечественные (Г. В.Колшанский, Г.Л.Пермяков, Е.Л. Вилинбахова) исследователи, изучая стереотип как интердисциплинарный феномен, выделили несколько его типов: социальный, ментальный, этнический, речевой и пр.

Под этническим стереотипом понимается схематичное стандартизированное представление о тех или иных этносах, обычно эмоционально окрашенное и обладающее высокой устойчивостью [3].

В лингвистике стереотип стал объектом нового направления лексикологических исследований: стереотипами все чаще называют особые единицы речи и языка - языковые и речевые клише [4, с.77]. Под термином «языковой стереотип» понимаются «устойчивые, повторяющиеся, а не возникающие случайно сообщения, которые закрепляются в коллективной памяти на уровне конкретики, соответствующей лексемам» [5, с. 13]. Языковые стереотипы могут быть представлены фразеологическими оборотами, поговорками, пословицами, клише, афоризмами, прибаутками, паронимами и другими устойчивыми сочетаниями. Иными словами, это единицы языка, описывающие представления о характере, обычаях и укладе жизни определенной нации. 
Языковые стереотипы разделяются на две большие смысловые группы: автостереотипы - устойчивые выражения, отражающие то, что люди думают сами о себе, и гетеростереотипы - обороты, содержащие представления относительно других народов [6].

Исследователи указывают на особенность, присущую автостереотипам: на их основе происходит идеализирование собственного этноса, поддержание наиболее самобытных качеств национального характера, нивелирование отрицательных черт. Через гетеростереотипы часто передаются антропологические характеристики, обусловленные внешним обликом индивида [7, с. 255]. Например, турки полагают, что цвет кожи арабов намного темнее, чем у самих турок.

В современном турецком языке число выражений, содержащих автостереотип «турок», невелико. В двухтомнике “Atasözleri ve deyimler sözlüğü” («Сборник пословиц и устойчивых выражений») турецкого лингвиста О.А. Аксоя мы встречаем три паремические единицы, описывающие турецкий национальный характер:

Türk’ün aklı gözünde 'Ум турка в его глазах’. (Турок верит только увиденному.)

Türk’ün aklı sonradan gelir 'Ум турка приходит позже'. (Говорят в случае необдуманного поступка.)

Türk karır, kılıcı karımaz 'Турок может состариться, но его меч - никогда’. (Даже в старости турок будет сражаться как молодой воин.) [8, с. 450].

На сайте TDK (Türk Dili Kurumu, Турецкого лингвистического общества) приводится лишь последняя паремия [9].

В турецком обществе, которое негомогенно по своему национальному и социальному составу, почти не используются автостереотипы. Более популярны социальные и топографические устойчивые наименования, составляющие два подкласса автостереотипов.

О появлении социальных стереотипов стали говорить относительно недавно. Популяризированные журналистами и писателями, а затем перешедшие в повседневную речь автостереотипы beyaz Türk 'белый турок', siyah Türk 'черный турок' и gri Türk 'серый турок' отражают социальное расслоение турецкого общества, сформировавшееся в конце XX в. Белый цвет, обычно символизирующий чистоту и избранность народа, служит для обозначения горожан, элитной прослойки общества. Черный цвет, контрастирующий с белым, обозначает бедный класс общества - необразованных простолюдинов, весьма религиозных, более привязанных к традиционной культуре и за это чаще всего презираемых классом «белых». Эти автостереотипы, появившись в книге журналиста У.Гюльдемира «Техас Малатья» (“Teksas Malatya”) [10] в 1992 г., были впоследствии подхвачены социологом Н. Гёле и писателем М. Секманом в книге “Türk usulü başarı” («Успех по-турецки») [11].

В современной Турции различные влиятельные персоны не боятся публично заявить о своей принадлежности к классу «черных» турок в целях привлечения симпатий более бедных слоев населения. О третьей группе, так называемых «серых» турках, пишет турецкий исследователь М.Акйол: «...“серый” класс сочетает в себе следование исламским религиозным традициям с урбанизированной прогрессивностью (хорошее образование, признание западной культуры и научных достижений)» $[12$, с.9]. Американский социополитолог Р. Касторьяну в од- 
ной из своих работ упоминает еще один термин - «евротурок», употребляемый в отношении группы людей, более образованных, имеющих полное представление о мире, мобильных, свободно говорящих на иностранных языках [13, с. 88-89]. Появлению этого стереотипа способствовала проводимая «белыми» турками в начале этого столетия националистическая политика под лозунгом «Станем более европейскими, чем сами европейцы». Весьма успешная, эта политика послужила укреплению авторитета страны на мировой арене. Однако термин «евротурок» не стал популярным.

Анализ существующих в современном турецком языке топографических автостереотипов позволяет сделать вывод о том, что за жителями некоторых населенных пунктов закрепилась определенная стереотипизация. Приведем несколько примеров.

Afyon'un kaymağı, Konya'nın manyă̆ı 'Афьон славен каймаком', Конья сумасшедшими'. (Так говорят, когда сталкиваются с необдуманными поступками жителей Коньи.)

Gavur İmir 'гявурский Измир'. (Измир известен как город, в котором исторически проживает большое количество греков-христиан. Стереотип отражает недоверие, особое отношение жителей Центральной Анатолии к жителям этого города.)

İmir'in havasıyla, kızına güven olmaz 'В Измире нельзя доверять погоде и девушкам’. (Погода в Измире так же изменчива, как и настроение измирских девушек.) Приведенное выражение может рассматриваться и как гендерный стереотип.

Karamanın koyunu, sonra çıkar oyunu. 'От овцы из Карамана можно ждать подвоха'. (По одной из легенд, это выражение возникло после того, как воины из Карамана, накрывшись овечьими шкурами, разгромили вражеское войско.)

Полиэтничность Турции отразилась и на гетеростереотипах в отношении различных наций. Рассмотрим примеры, используемые в литературе и научных трудах.

В работе американской исследовательницы Э.Г.Амброс “The Other (non-Muslim, non-Ottoman) in Ottoman literary humour” («Другие (немусульмане, неоттоманцы) в османской юмористической литературе») представлены одни из первых литературных примеров стереотипизированного юмора и сатиры в отношении «других» народов, не являвшихся османами и мусульманами. В турецкой литературе юмор и сатира по отношению к самим османам не были распространены, более того, они находились под жесткой цензурой [14, с. 87]. Площадкой для упражнений в сатире был так называемый юмористический календарь “Mizāhī Takvīm” («Мизахи Таквим») XVI в. поэта Зати. Автор в коротких и ироничных зарисовках описывает представителей этнических меньшинств.

Как и все поэты той эпохи, Зати был осторожен при выборе объекта иронии. Поэты, в круг которых не входили армяне и евреи, должны были подумать дважды, прежде чем писать о еврее, который лечил членов его семьи. Соседские и дружеские взаимоотношения ценились, ими не пренебрегали.

${ }^{1}$ Каймак - кисломолочный продукт, нечто среднее между сметаной, сладким творогом и сливочным маслом. Раньше считался продуктом для богатых. 
Открытому иронизированию подвергалась самая незащищенная часть населения - цыгане. И если относительно других народностей использовались различные литературные приемы (двойные смыслы и аллюзии), то ирония в отношении цыган зачастую больше походит на сатиру. Это хорошо проиллюстрировано в творчестве поэта XVI в. Факири:

Nedür bildüy mi çingāne cihānda 'Понял ли ты, кто такие цыгане в этом мире?'

Gezerler hāne-be-hāne yabanda 'Бродят от дома к дому на чужбине' [14, c. 89].

Ayucılarda kimseler ola ki yüzin gören ayı gördüm sana 'Есть среди этих предводителей медведей такие, увидев чьи лица, подумаешь, что видел медведя’ [14, с.89].

Уникальный материал содержит произведение османского поэта XIX в. Эндерунлу Фазыла (1757-1810) "Hūbānnāme ve Zenānnāme” («Книга прекрасных мужей и прелестных женщин»). Поэт попытался описать все народы (их основные характеристики, в том числе интимные сферы жизни), которые ему встречались на жизненном пути или о которых он слышал. Цыганским женщинам дана нелестная оценка, а цыганским мужчинам - наоборот, - они хорошие музыканты и танцоры. Автор уделяет особое внимание и полякам, полагая, что у них еврейские корни.

Gerçi nāzikdür o pākīze beden 'Однако их тела очень красивы'.

Neylerem aşlı Yahüdīlerden 'Но что мне делать с этими (женщинами), еврейками по происхождению?’ [14, с.93].

Еще одним произведением, где можно найти, по словам самого автора, который неизвестен, описание всех национальностей Стамбула, является "Risale-i garibe” («Книга о странных вещах»). Написанная в конце XVII - начале XVIII в., она содержит своего рода социальную сатиру, основанную на предубеждениях автора:

Şakalı köse ile ve [sic] gãyet gök gözli cühüddan hayr uman' Те, кто верит, что добро может прийти от жидобородых (безбородых) и голубоглазых евреев (у которых глаза цвета неба)'.

Данное высказывание основано на поверье, что человек с голубыми глазами иноверец, чужак - может сглазить, навести порчу [14, с.94].

Российские ученые также интересовались вопросом межэтнических отношений. Работу тюрколога В. А. Гордлевского «Силуэты Турции» можно по праву считать первым исследованием языковых стереотипов турецкого языка. Автор, с большой теплотой относившийся к простому турецкому народу, описывает Анатолию как «живой этнографический музей под открытым небом» [15, с. 15]. В частности, он анализирует пословицы с точки зрения того, «как смотрел османец на народы, с которыми он сталкивался в своем государстве» [16, с.270], четко подмечая все его характерные черты. Исследователь приводит пример первых автостереотипов турок, помогая нам проследить, как проявлялось и изменялось их отношение к самим себе: от уважительного (У османиа изарское величие...) до пренебрежительного (Турок может быть ученым, но он не может быть человеком). Общая картина, описанная В.А. Гордлевским, практически вторит выводам, представленным в работе Э.Г. Амброс. 
Мы же, в свою очередь, приведем те выражения, которые используются в современном турецком языке.

\section{О евреях:}

Çıfıt груб. 'еврей', 'иудей'

Çıfıt çarşısı ‘бедлам', ‘бардак’. (Ortalık çıfıt çarşısına döndü ‘Повсюду бардак’)

Çıfıt orucu 'еврейский пост’: волокита, канитель.

Yahudi pazarlı̆̆ı 'еврейский торг'.

Bugün pazar, gavurlar / Yahudiler azar 'Сегодня воскресенье, гявуры’ / 'Евреи будут разгневаны'[17].

Об армянах и греках:

Ermeni! 'Армянин!' - в значении «жестокий, мучитель, предатель» (таким эпитетом может наградить мать ребенка, который совершил ужасный поступок).

Ermeni feneri gibi dönmek 'выкручиваться как армянский фонарь’ (предатель, ищущий выгоду для себя).

Ermeni gelini gibi (kırtmak) ‘заигрывать (кокетничать) как армянская невеста’.

Ermeni dölü / Ermeni tohumu / Rum dölü / Rum tohumu 'армянское (греческое) отродье'.

Agop’un kazı gibi yutmak / bakmak 'как гусь Агопа 2 проглотить еду в один присест' / 'смотреть пустым взглядом, с глупым выражением' [17].

\section{О цыганах:}

В период нахождения у власти А. Мендереса, премьер-министра Турции (19501960), цыган стали называть esmer vatandaş 'смуглый гражданин' [18, с. 76].

Arabacı 'водитель'. Такое прозвище цыгане получили из-за профессии, которой они преимущественно занимаются.

72 buçuk millet 'семьдесят два с половиной народа'. Под числом 72 понимают народы мира, весь мир, «половина» обозначает цыган.

Çingene eşeği önden gider 'Осел цыгана идет перед ним'. Подчеркивается недалекость цыган: они ведомы ослами.

Çingen hesabı yapmak 'делать цыганский подсчет’: мелочиться.

Çingene borcu 'цыганский долг': мелкий, неважный долг.

Çingene çergesi / çadırı 'цыганский шатер': трущобы, грязное место.

Çingene çorbası 'цыганский суп’: хаос, путаница, неразбериха.

Çingene evinde kaymak eğlenmez / bulunmaz 'В доме цыгана каймак не найдешь' (Каймак, молочный продукт наподобие сливок или сливочного масла, считался роскошью, т. е. «хорошего ничего не найдешь».)

2 По одной из версий, в Турции проживал армянин по имени Агоп, он разводил гусей, которых кормил особым, им изобретенным способом. 
Çingene kavgası 'цыганская ссора, потасовка'. Подчеркивается характер цыган, которые ругаются шумно, с бранью.

Çingeneden çoban olmaz, Yahudiden pehlivan 'Из цыгана не выйдет пастух, из еврея - богатырь' Выражает недоверие к цыганам, за которыми закрепилась недобрая слава конокрадов, и к евреям, которых недолюбливали за трусливость, нежелание сражаться на чьей-либо стороне [17].

\section{О курдах:}

dağlı Türkler 'горные турки'. Термин появился благодаря работе М.Ш.Фырата “Doğu İlleri ve Varto Tarihi” («Восточные районы и история Варто») в 1945 г. [19; 20]. В ней речь идет о курдах как о народе, говорящем на языках курманджи и зазаки. В течение долгих лет в Турции данный термин использовался в качестве замены слова «курды» с целью вывести последнее из речевого употребления.

Hasso, Memo(lar) 'Хассо', 'Мемо', вошло в обиход с подачи турецкого политика Дж. К.Инджедайи, использовавшего эти два апеллятива (формы курдского звательного падежа личных имен Hasan - Hasso, Memet/Mehmet - Memo) для обозначения курдского народа [21, с. 101].

A ğaçtan maşa, Kürt’ten paşa olmaz 'Как из дерева не получатся щипцы, так и из курда - паша (правитель)'. В работе В.А. Гордлевского находим: «Паша не получится из араба...» [16, с.272]. Приведенные примеры представляют интерес и для диахронического изучения стереотипных выражений в турецком языке: то, что раньше говорили про араба, в настоящее время говорят о курде.

Alavere dalavere, Kürt Memet nöbete 'Опять двадцать пять, курд Мемет на дежурство опять'. Говорят о ситуации, когда выполнение обязанностей перекладывается на другого, более слабого и незащищенного, в данном случае - курда.

Çingene çalar, Kürt oynar 'Цыган играет, курд танцует’. Подчеркиваются основные таланты этих народов. Говорят в случаях, когда они отлынивают от работы: им бы не работать, а только развлекаться - один играет, другой танцует.

En iyi Kürt, ölü Kürt'tür 'Хороший курд - мертвый курд'. Произнесенная Ф.Шериданом фраза «Хороший индеец - мертвый индеец», ставшая американским афоризмом, перешла в турецкий язык с тем отличием, что «индеец» стал «курдом». Однако, как замечают сами носители языка, в ней может быть использован любой этноним в зависимости от ситуации.

Kıro - курд. «мальчик, юноша» (произносится и как «кро»). Слово, пришедшее из курдского языка, турками стало использоваться в качестве обращения, а также для обозначения провинциальности человека в его внешнем виде и поведении.

\section{Об арабах:}

Anladıysam Arap olayım 'Быть мне арабом, если я что-то понял’. Говорят в случае, если ситуация запуталась, стала непонятной.

Kahve içersen Arap olursun 'Если выпьешь кофе, станешь арабом' (в значении «станешь темнокожим»). Так говорят, чтобы запугать детей и удержать их от употребления кофе как можно дольше. 
Arap saçına dönmek 'превратиться в арабский волос': превратиться в хаос, запутаться.

Ne Şam’in şekeri, ne Arab’n yüzü̈ 'Ни сладости из Дамаска, ни лицо араба (видеть не хочу)'. Так говорят о нежелательных персонах.

О противоречивом отношении турок к арабам еще в прошлом веке писал В. А. Гордлевский: «...с одной стороны, благоговейное отношение к арабскому языку Корана, с другой - антипатия к самому народу» [16, с. 272]. Выражения, перечисленные выше, были упомянуты в работе российского исследователя, однако употребляются и в наши дни, ничуть не утратив актуальность и семантику.

\section{О лазах:}

Laz kafalı 'лазская башка' (в значении «дурак»; лаз ассоциируется с несообразительным человеком, тугодумом).

Laz, Kürd’ün deniz görmüş halidir 'Лаз - это увидевший море курд’.

Lazın kafası 12'den sonra çalışmaz 'Голова лаза не работает после двенадцати'. Днем, когда жарко, лазы не работают, спят.

Laz damarı ‘лазское упрямство’. Говорят, когда человек упрямится: в тебе есть чтото от лазов / лазское упрямство.

Laz akl, kaz aklı 'Лазский ум - гусиный ум’. Считается, что гусь - глупая птица, а у лаза столько же ума, сколько у гуся.

\section{О разных народах:}

Arnavut inadı 'албанское упрямство'.

Arnavut'a sormuşlar: 'Cehenneme gider misin?’ diye, 'Aylık kaç?’ demiş. 'У албанца спросили: «В ад пойдешь?». «А сколько платят в месяц?» - спросил он'.

Fransız kalmak 'остаться французом'. Обычно говорит третий человек, который, возможно, позже присоединился к беседе и не понимает, о чем речь.

Moskof gavuru 'московский гявур'. Обращение Moskof упоминает В.А.Гордлевский, который слышал его еще в студенческие годы [16, с.175]. Возникнув в период холодной войны, это выражение имеет силу до сих пор и включено в словарь TDK.

Языковой стереотип может быть представлен и метафорическим оборотом: за определенным словом закреплен образ, характеристики, которые его определяют:

арас̧і 'хиппи’ (образ индейцев апачи спроецировался на стиль одежды и поведение молодых людей);

gündüz feneri 'дневной фонарь' (светится днем): темнокожие;

${ }^{3}$ Словом yӥzӥ заменяют слово zekeri в оригинальной версии в связи с его неэтичным значением. 
gavur 'гявур, неверующий, немусульманин'. Носит сугубо негативный характер: «не такой, как мы», «не верит в единого Бога», ему нельзя доверять и т. п.;

gavur icadı 'гявурское изобретение' - говорят про какой-то предмет/устройство/ аппаратуру, которое было сделано не турками, освоение которого вызывает сложности, а в результате раздражение (часто - ругательство);

gavur inadı 'гявурское упрямство';

gavur etmek / gavur olmak 'испортить, промотать(ся)';

gavur eziyeti 'гявурская пытка, издевательство';

Gavur gavurluğunu yapar 'Гявур (все равно) сделает свою гявурность'. В значении «от дурного добра не жди».

Большое количество жаргонных выражений (арго) образовано со словом papaz 'поп, священник': papaz olmak 'поссориться, разругаться'; рараz uçurmak 'устроить попойку'; рараzсл 'шулер, обманщик' и т.д. Отдельно этим словом называют длинноволосых молодых людей.

Человек, изучающий турецкий язык, вступая в коммуникацию с носителями, сталкивается с огромным количеством языковых стереотипов. Применяя их в речи, он часто полагает, что то или иное турецкое выражение имеет абсолютный аналог в его родном языке. Однако говорящий чаще всего наблюдает непонимание со стороны собеседника или неприятие его поведенческой линии. Это явление объясняется в социолингвистике как невладение кодом «свой - чужой», применимым к разным социальным группам. В процессе социализации индивидуум, устанавливая границы между «своим» и «чужим», между «хорошо» и «плохо», переносит приобретенный им ранее языковой опыт на новые явления [21, с. 202]. Приведем мнение американского ученого Х. Патнэма, который подчеркивал, что «стереотипы обладают лингвистической принудительностью в том же смысле, в каком такой принудительностью обладают грамматические правила» [22, с. 52].

Швейцарский лингвист Ш.Балли писал, что в его понимании «речь как явление глубоко социальное представляет собой комплекс символов, обладающих свойством давать ее носителю социальную характеристику, она может также отражать стремление отдельной личности приспособиться к другим членам данной общественной группы» [23, с.17]. Очевидно, «когда индивидуум желает влиться в группу, в которой его пока не признают за своего, он начинает все чаще употреблять в речи стереотипы, являющиеся для данной группы нормой <...> Эти “благоприобретенные” стереотипы являются связующим звеном между индивидуумом и группой, которой он симпатизирует» [24, с. 135].

Использование неносителем гетеростереотипных выражений с отрицательным оттенком часто не приветствуется и не вызывает восхищения у носителей языка даже при отличных лингвистических познаниях говорящего. Употребить тот или иной этностереотип может позволить себе человек, владеющий языком на самом высоком уровне и тонко чувствующий настроение собеседников. Ведь коммуникация, как писал Е.Бартминский, есть не что иное, как «программирование поведения в рамках определенной социальной группы» [25, с. 186].

«Культуросфера определенного этноса содержит ряд элементов стереотипного характера, которые, как правило, не воспринимаются носителями другой культу- 
ры» $[26$, с. 116]. Однако «носители языка владеют культурным кодом, благодаря которому они интерпретируют значение фразеологизма как на сознательном уровне, так и на уровне бессознательного» [26, с.116]. На этот факт указывает и Е.Ф.Тарасов: «Главная причина непонимания при межкультурном общении не различие языков - сформировать навыки говорения (письма) и слушания (чтения) сравнительно просто, а различие национальных сознаний коммуникантов» [27, с. 22].

То небольшое число стереотипных выражений, которое рассмотрено в статье, не претендует на отражение всей языковой картины мира турок. В турецкой ментальности, как и в любой другой, запечатлены в той или иной степени наиболее значимые социально-культурные события, содержатся косвенные или прямые ссылки на исторические реалии, отражены межнациональные конфликты, имеются и свои «этнические изгои». Лишь путем анализа языковых стереотипов (а, на наш взгляд, это представляется невозможным без проведения серьезных диахронических исследований как фразеологического фонда турецкого языка, так и социокультурных и антропологических данных) можно будет максимально полно описать турецкую языковую картину мира.

Владение языком в условиях современного общества - это не просто грамматические знания и навыки, это и усвоение языковых стереотипов. Любое неверное понимание или ошибочное использование аутентичного выражения может привести к непоправимым конфликтным ситуациям. Исследователи-тюркологи должны направить все усилия на разработку и подготовку культурологических словарей и словарей реалий турецкого языка. К сожалению, закономерности перевода этностереотипов слабо изучены и в турецком языке. На это явление обращал внимание Н. Д. Финкельберг, который ввел термин «клише (стереотип)». Он говорил о «слабо изученном явлении перехода лингвокультурных стереотипов одного языка в лингвокультурные стереотипы другого языка при межъязыковых контактах» [28, с.89-90].

Общение между представителями различных культур невозможно без знания их культурологических особенностей. Всестороннее изучение стереотипов, используемых носителями турецкого языка в повседневной коммуникации, могло бы способствовать выявлению причин многих социальных, политических, психологических и межэтнических конфликтов. Наша работа может послужить основой для дальнейшего изучения языковых стереотипов турецкого языка.

\section{Литература}

1. Мацумото Д. Психология и культура. 1-е изд. СПб.: Питер, 2003. 720 с.

2. Краткий словарь когнитивных терминов / под общ. ред. Е.С.Кубряковой. М.: Филол. ф-т МГУ им. М. В. Ломоносова, 1997. 245 с.

3. Словарь социолингвистических терминов / отв. ред. В. Ю. Михальченко. М., 2006. 315 с.

4. Нелюбин Л.Л. Толковый переводоведческий словарь. 3-е изд., перераб. М.: Флинта; Наука, 2003. 320 c.

5. Бартминский Е. Базовые стереотипы и их профилирование // Стереотипы в языке, коммуникации, культуре: сб. ст. / сост. и отв. ред. Л. Л. Федорова. М.: РГГУ, 2009. С. 11-21.

6. Психология общения: Энциклопедический словарь / под общ. ред. А. А. Бодалева. М.: КогитоЦентр, 2011. 600 с.

7. Тер-Минасова С. Г. Война и мир языков и культур. М.: Слово, 2008. 334 с.

8. Aksoy Ö. A. Atasözleri ve Deyimler Sözlügü. İstanbul: İnkilap Kitabevi, 2012. 487 s.

9. URL: http://tdk.gov.tr/index.php?option=com_atasozleri\&arama=kelime\&guid=TDK. GTS. $58908 \mathrm{f}$ cb9d8945.70854142 (дата обращения: 23.05.2016). 
10. Güldemir U. Teksas Malatya. İstanbul: Tekin Yayınevi, 1992. $463 \mathrm{~s}$.

11. Sekman M. Türk usulü başarı. İstanbul: Alfa yayınları, 2003. $350 \mathrm{~s}$.

12. Akyol M. İçimizden Birileri: Beyaz Türkler // Sizıntı. URL: http://sizinti.com.tr/konular/ayrinti/ icimizden-birileri-beyaz-turkler.html (дата обращения: 16.05.2011).

13. Kastoryano R. Turkey between Nationalism and Globalization. London: Routledge, 2013. 240 p.

14. Ambros E. G. The Other (non-Muslim, non-Ottoman) in Ottoman literary humour // Türklük Bilgisi Araștırmaları. Journal of Turkish Studies. 2015. No 44. P. 85-100.

15. Гордлевский В. А. Избранные сочинения: в 4 т. М.: Изд-во восточ. лит-ры, 1968. Т. 4: Этнография, история востоковедения, рецензии. $613 \mathrm{c.}$

16. Гордлевский В.А. Избранные сочинения: в 4 т. М.: Изд-во восточ. лит-ры, 1961. Т.2: Язык и литература. $560 \mathrm{c}$.

17. URL: http://ayrimcisozluk.blogspot.com.by/search?updated-max=2012-02-15T14:50:0008:00\&max-results=15 (дата обращения: 31.01.2017).

18. Yıldız H. Türkçede Çingeneler için Kullanılan Kelimeler ve Bunların Etimolojileri // Dil Araştırmaları Dergisi. Cilt: 1 Sayı: 1. Ankara: Gazi Üniversitesi, 2007. S. 61-82.

19. Fırat M. Ş. Doğu illeri ve Varto Tarihi. İstanbul: Saka Matbaası, 1948. 336 s.

20. Bıçakçı B. Popüler siyasi deyimer sözlüğü. İstanbul: İletişim yayın evi, 1995. $255 \mathrm{~s}$.

21. Третьякова Т.П. О лингвистической интерпретации современных стереотипов // Вестник ЛГУ им. А. С.Пушкина. 2015. Вып. 1. Т. 7. С. 201-208.

22. Макеева Л. Б. Философия Х. Патнэма. М.: ИФ РАН , 1996. 190 с.

23. Балли Ш. Французская стилистика. 2-е изд., стереотип. М.: Эдиториал УРСС, 2001. 392 с.

24. Квастхофф У. Социальный предрассудок и коммуникация - лингвистический анализ стереотипа // От лингвистики к мифу: лингвистическая культурология в поисках этнической ментальности: сб. ст. / сост. А. В. Павлова. СПб.: Антология, 2013. 352 с.

25. Бартминский Е. Языковой образ мира: Очерки по этнолингвистике. М.: Индрик, 2005. 528 с.

26. Давлетбаева Д.Н. Исследование процесса восприятия окказиональных фразеологических единиц в психологическом эксперименте на материале генетически неродственных языков // Интеграция образования. 2011. Вып. 3. С. 114-120.

27. Тарасов Е.Ф. Межкультурное общение - новая онтология анализа языкового сознания // Этнокультурная специфика языкового сознания. М.: ИЯ РАН, 1996. С. 7-22.

28. Финкельберг Н. Д. Теория перевода арабского языка. Курс лекций. М.: Военный ин-т, 1977. $207 \mathrm{c}$.

Для цитирования: Сарыгёз О.В. Языковые авто- и гетеростереотипы в турецком языке // Вестник СПбГУ. Востоковедение и африканистика. 2017. Т. 9. Вып. 2. С.125-136. DOI: 10.21638/11701/ spbu13.2017.201.

\section{References}

1. Matsumoto D. Psikhologiia i kul'tura [Psychology and Culture]. St. Petersburg, Piter, 2004. $1^{\text {st }}$ ed. 720 p. (in Russian)

2. Kratkii slovar' kognitivnykh terminov [A short dictionary of cognitive terms]. Ed. by E. S. Kubriakova. Moscow, Lomonosov Moscow State Univ., 1997. 245 p. (in Russian)

3. Slovar' sotsiolingvisticheskikh terminov [Glossary sociolinguistic terms]. Ed. by V. Iu. Mikhal'chenko. Moscow, 2006. 315 p. (in Russian)

4. Neliubin L. L. Tolkovyi perevodovedcheskii slovar' [Explanatory translator Dictionary]. $3^{\mathrm{d}}$ ed. Moscow, Flinta; Nauka Publ., 2003. 320 p. (in Russian)

5. Bartminskii E. [Basic stereotypes and profiling]. Stereotipy v iazyke, kommunikatsii, kul'ture: sb. st. [Stereotypes in language, communication and culture]. Comp. and ed. by L. L. Fedorova. Moscow, RGGU Publ., 2009, pp.11-21. (in Russian)

6. Psikhologiia obshcheniia: Entsiklopedicheskii slovar' [Psychology of communication. Encyclopedic Dictionary]. Ed. by A. A. Bodalev. Moscow, Kogito-Tsentr Publ., 2011. 600 p. (in Russian)

7. Ter-Minasova S. G. Voina i mir iazykov i kul'tur [War and World Languages and Cultures]. Moscow, Slovo Publ., 2008. 334 p. (in Russian) kish)

8. Aksoy Ö. A. Atasözleri ve Deyimler Sözlüğ̈̈. İstanbul, İnkilap Kitabevi Publ., 2012. 487 p. (in Tur-

9. Turkish Language Association. Available at: http://tdk.gov.tr/index.php?option=com_atasozleri\&ara ma=kelime\&guid=TDK.GTS.58908fcb9d8945.70854142 (accessed: 31.01.2017). 
10. Güldemir U. Texas Malatya. Tekin Yayınevi, 1992. 463 p. (in Turkish)

11. Sekman M. Turkisch success. Alfa yayınları, 2003. 350 p. (in Turkish)

12. Akyol M. Someone among us: White Turks. Sizintı. Available at: http://sizinti.com.tr/konular/ayrinti/icimizden-birileri-beyaz-turkler.html. (in Turkish)

13. Kastoryano R. Turkey between Nationalism and Globalization. London, Routledge, 2013. 240 p.

14. Ambros E. G. The Other" (non-Muslim, non-Ottoman) in Ottoman literary humour. Journal of Turkish Studies. Türklük Bilgisi Araştırmaları, 2015, no. 44, pp. 85-100.

15. Gordlevskii V. A. Izbrannye sochineniia: v 4 t. T. 4. Etnografiia, istoriia vostokovedeniia, retsenzii [Selected works: in 4 vols. Vol. 4. Ethnography, History of Oriental Studies, reviews]. Moscow, Publ. vostoch. lit-ry, 1968. 613 p. (in Russian)

16. Gordlevskii V. A. Izbrannye sochineniia: $\mathrm{v} 4$ t. T. 2. Iazyk i literatura [Selected works: in 4 vols. Vol. 2. Language and literature]. Moscow, Publ. vostoch. lit-ry, 1961. 560 p. (in Russian)

17. Discriminatory vocbulary. Available at: http://ayrimcisozluk.blogspot.com.by/search?updated$\max =2012-02-15 \mathrm{~T} 14: 50: 00-08: 00 \& \max -$ results=15 (accessed: 31.01 .2017 ).

18. Yıldız H. İdioms about the Roma in Turkey and their etymology Türkçede. Dil Araştırmaları Dergisi. Cilt: 1 Sayı: 1. Ankara, Gazi Üniversitesi, 2007, pp. 61-82. (in Turkish)

19. Firat M. S. Eastern regions and the history of Varto. Saka Matbaass, İstanbul, 1948. 336 p. (in Turkish)

20. Bıçakçı B. Popular political idiom dictionary. İletişim yayın evi, 1995. 255 p. (in Turkish)

21. Tret'iakova T.P. O lingvisticheskoi interpretatsii sovremennykh stereotipov [On the linguistic interpretation of contemporary stereotypes]. Bulletin of Pushkin Leningrad State University, 2015, issue 1, vol.7, pp. 201-208. (in Russian)

22. Makeeva L. B. Filosofiia Kh. Patnema [H.Putnam' Philosophy]. Moscow, IF RAN Publ., 1996. 190 p. (in Russian)

23. Balli Sh. Frantsuzskaia stilistika [French stylistics]. $2^{\text {nd }}$ ed. Moscow, Editorial URSS, 2001. 392 p. (in Russian)

24. Kvastkhoff U. [Social prejudice and communication - linguistic analysis of the stereotype]. Ot lingvistiki $k$ mifu: lingvisticheskaia kul'turologiia $v$ poiskakh etnicheskoi mental'nosti: sb. st. [From the myth of linguistics: linguistic culture studies in search of ethnic mentality]. Comp. by A. V. Pavlov. St. Petersburg, Antologiia Publ., 2013. 352 p. (in Russian)

25. Bartminskii E. Iazykovoi obraz mira: Ocherki po etnolingvistike [Language Image of the World: Essays on ethnolinguistics]. Moscow, Indrik Publ., 2005. 528 p. (in Russian)

26. Davletbaeva D. N. Issledovanie protsessa vospriiatiia okkazional'nykh frazeologicheskikh edinits v psikhologicheskom eksperimente na materiale geneticheski nerodstvennykh iazykov [Investigation of the process of perception of occasional phraseological units in a psychological experiment on the material of genetically unrelated languages]. Integratsiia obrazovaniia [Integration of education], 2011, issue 3, pp. 114120. (in Russian)

27. Tarasov E. F. [Intercultural communication - a new ontology analysis of language consciousness]. Etnokul'turnaia spetsifika iazykovogo soznaniia [Ethnocultural specificity of linguistic consciousness]. Moscow, IIa RAN Publ., 1996, pp.7-22. (in Russian)

28. Finkel'berg N.D. Teoriia perevoda arabskogo iazyka. Kurs lektsii [Theory of translation of the Arabic language. Lecture course]. Moscow, Voennyi in-t Publ., 1977. 207 p. (in Russian)

For citation: Sarigoz O. V. Language Autostereotypes and Heterostereotypes in Turkish. Vestnik SPbSU. Asian and African Studies, 2017, vol.9, issue 2, pp. 125-136. DOI: 10.21638/11701/spbu13.2017.201.

Статья поступила в редакцию 13 июля 2016 г. Статья рекомендована в печать 28 февраля 2017 г.

Контактная информация

Сарыгёз Ольга Владимировна - соискатель; olgasarby@yandex.ru

Sarygoz Olga V. - Postgraduate; olgasarby@yandex.ru 